\title{
SELECCIÓN DE EMPLAZAMIENTOS PARA VERTEDEROS CONTROLADOS
}

\section{(ELECTION OF SANITARY LANDFILL SITES)}

Marcos del Pozo Manrique, Departamento de Proyectos y Planificación Rural E.T.S. de Ingenieros de Montes. Universidad Politécnica. MADRID/ESPAÑA

Fecha de recepción: 25-X-90 $113-10$

\section{RESUMEN}

El objetivo del presente trabajo es aportar algunas ideas sobre la estrategia básica para la correcta ubicación de vertederos controlados. Para ello se abordan tres temas:

- Problemática de los residuos sólidos urbanos y soluciones técnicas aportadas por el vertido controlado, indicando su campo de aplicación así como las principales interacciones con el medio de este tipo de instalación.

- A la vista de esta información previa, definición de los principales requisitos exigibles a nuestro juicio al territorio para la ubicación de un vertedero, asi como los criterios para su valoración y selección.

- Por último, aplicación a la selección de emplazamientos para el vertido controlado en un territorio concreto, en este caso la comarca de Alcalá de Henares, en la provincia de Madrid.

Debido a que el vertido controlado es un medio de eliminación en el que el principal agente técnico es el mismo terreno donde se asiente la instalacion, pensamos que una correcta ubicación es la principal garantía para obtener unos niveles duraderos de seguridad ambiental y un comportamiento adecuado en las vertientes económica y social.
SUMMARY

The objetive of this article is to bring forward some ideas about the method for the correct election of sanitary landfill sites.

Three subjects are developed:

- Solid wasting problem and their technical solutions.

- Territorial qualification for sanitary landfilling.

- Aplication to a particulary territory: the Alcala de Henares area, in the Madrid province.

The ground is the principal agent is sanitary landfilling, so the correct design of sites is essential to obtain high levels of enviromental safety.

\section{LOS RESIDUOS SÓLIDOS Y EL VERTIDO CONTROLADO}

El carácter residual de un producto depende más del contexto en que se genera que de su propia naturaleza.

Consideramos como desechos, aquellos productos que han perdido su valor como bien de producción o consumo y sobre los que existe una demanda de retirada o eliminación.

Por tanto nos encontramos ante una noción muy rela- tiva y variable, sin un contenido cualitativo fijo, de tal modo que cualquier tipo de sustancia puede ser residual en función del ámbito en que se encuentren.

Una característica "activa" de aquello que consideramos como residuo es su carácter nocivo o, al menos, molesto para la colectividad que lo produce. Esta característica va desde el caso evidente de los residuos tóxicos, hasta el más ambiguo de los residuos inertes, por ejemplo, cuyo carácter indeseable deriva principalmente de "estar en un lugar que no les corresponde". 


\section{l.1. Clasificación de los residuos}

Debido al carácter inespecífico del concepto de residuo y a la gran variedad de realidades que pueden englobarse en él, las clasificaciones existentes son muy numerosas y a menudo complejas.

Bajo nuestro punto de vista enfocado al vertido, conviene en principio hacer una distribución muy sencilla pero de gran trascendencia práctica:

a) Residuos sólidos: son los únicos susceptibles de vertido controlado aunque, como veremos, no todos.

b) Residuos líquidos: sólo les es aplicable el vertido con un tratamiento previo de desecación [deben pasar a la categoría a) ].

c) Residuos gaseosos: tienen sus propias técnicas de tratamiento, completamente ajenas al vertido controlado.

Por tanto, a partir de ahora nos referiremos exclusivamente a los residuos sólidos, y dentro de ellos haremos una precisión mayor eliminando aquéllos de origen agropecuario y forestal que tienen sus propios mecanismos de reutilización y eliminación en el ámbito en que se originan. Por tanto haremos referencia a residuos sólidos urbanos, que pueden desglosarse en 6 grandes grupos: (1)

1: Residuos domiciliarios y asimilables (*).

2: Residuos inertes (*).

3: Residuos procedentes de maquinaria desechada.

4: Residuos tóxicos o peligrosos, fundamentalmente de origen industrial.

5: Residuos procedentes de centros sanitarios.

6: Lodos desecados procedentes de plantas depuradoras.

Los 2 grupos (1 y 2) marcados con (*) son aquéllos a los que es aplicable el vertido controlado en sus modalidades convencionales.

Los grupos 4 y 5 no son susceptibles de vertido ordinario y tienen sus propias técnicas de tratamiento y eliminación (depósitos de seguridad, incineración, etc.).

Los grupos 3 y 6 pueden disponerse en vertedero controlado bajo determinadas condiciones (ausencia de toxicidad en 6 y conformación adecuada en 3).

\subsection{Los residuos domiciliarios y afines}

Representan el contingente fundamental destinado a vertido que, a su vez, es el que condiciona en mayor grado las características e impactos del vertedero controlado.
Como veremos más adelante es fundamental conocer la producción y composición de este tipo de residuos para planificar el vertido.

Respecto a su composición, hay que decir que pueden presentar cualquier tipo de producto (todo aquel que el particular tire a la basura) incluidos aquéllos calificados como tóxicos, peligrosos o infectantes. Se asume, sin embargo, que la proporción de sustancias "problemáticas" se mantiene siempre en niveles moderados, pero su presencia debe tenerse muy en cuenta a la hora de planificar el vertido, pues de ellos se derivan los principales riesgos ambientales y sanitarios.

A continuación comentamos brevemente el papel res. pecto al vertido de algunos componentes típicos de los residuos domiciliarios: (*)

- Humedad: la incorporación de residuos con alto contenido en agua facilita la formación de lixiviados, así como incrementa los procesos de asenta. miento del vertedero.

- Materia orgánica fermentable (30-60\%): su proporción determina aspectos tan importantes como la elevación de la temperatura durante la fermentación aerobia (hasta $60^{\circ} \mathrm{C}$ ) y la producción de metano durante la fermentación anaerobia (entre 30 y $60 \mathrm{l} / \mathrm{t}$ de materia orgánica). Su descomposición y consiguiente reducción de volumen también incide sobre los asentamientos.

- Plásticos (3-12\%): ejercen un múltiple efecto negativo sobre la dinámica del vertedero:

* Vuelco fuera del recinto de vertido.

* Obstaculizan el tráfico de maquinaria por el frente de vertido al introducirse en las cadenas y sistemas de ventilación (2).

* Fomentan la anaerobiosis, actuando como aislantes.

* Pueden desprender gases tóxicos a altas temperaturas.

* Dificultan la implantación de vegetación sobre la superficie del vertedero clausurado, al ofrecer una barrera física para el crecimiento de las raíces.

- Papel (15-30\%): su principal efecto en el vertedero es la gran cantidad de agua que puede absorber (entre el 200 y el $300 \%$ de su peso), lo que puede ser muy favorable en relación a la producción de lixiviados (3). Comparte con los plásticos su facilidad para ser arrastrado por el viento fuera del recinto de vertido.

(*) Entre paréntesis: rango porcentual en peso (ámbito nacional). 
Ejemplos de sustancias tóxicas que pueden encontrarse en los residuos domiciliarios:

- Arsénico: sus derivados pueden presentarse en pinturas, barnices, insecticidas, etc. Bajo condiciones anaerobias aumenta su toxicidad.

- Plomo: no suele presentar problemas debido a su escasa movilidad, salvo algunas de su sales (carbonatos).

- Cadmio: procede de elementos eléctricos domésticos. Su poder polucionante aumenta a pH's bajos y se han detectado situaciones de contaminación en vertederos controlados.

- Cianuros: su vertido es sumamente peligroso incluso en depósitos de seguridad. Los riesgos de una eventual contaminación del agua son graves. Puede formarse gas cianhidrico (muy tóxico) por contacto con ácidos orgánicos presentes en el vertedero (4).

- Sulfatos: pueden originarse en grandes cantidades dentro del vertedero. Además de representar un riesgo de contaminación del agua, propician la emisión de gas sulfhídrico, extremadamente maloliente.

- Asbestos: su manipulación es peligrosa, pues la inhalación reiterada de sus fibras resulta cancerígena. Sin embargo, una vez alojado en el vertedero resulta prácticamente inocuo (es insoluble y no presenta toxicidad).

- Difenilos policlorados: productos de gran toxicidad cuya presencia en residuos domiciliarios puede deberse a papeles autocopiadores, barnices, plastificantes, etc. Afortunadamente son sustancias poco lixiviables, lo que limita sus riesgos en el contexto del vertido controlado.

\subsection{Concepto de vertedero controlado}

Se entiende por vertedero controlado la instalación destinada a la disposición de residuos sobre el terreno y su posterior cobertura con tierra compactada.

El carácter controlado de la instalación, requiere técnicas para evitar o minimizar los siguientes riesgos:

- Contaminación de las aguas superficiales o subterráneas.

- Formación de polvo y arrastre de residuos ligeros.

- Propagación de gases contaminantes o molestos.

- Acceso de animales a los residuos.

- Iniciación y propagación de incendios.
Parte de este "control" se ejerce merced a instalaciones adecuadas. Pero debido a que los residuos, una vez dispuestos, persisten indefinidamente, y con ellos los riesgos que se les asocian, se requiere un control ilimitado en el tiempo que sólo puede obtenerse mediante un emplazamiento correcto.

Debido al carácter de almacén indefinido de residuos el vertido controlado ha sido muy criticado. A continuación exponemos sus principales ventajas e inconvenientes:

\section{Ventajas:}

- Economía.

- Versatilidad.

- Sencillez técnica.

- Altos niveles de seguridad cuando está bien proyectado.

- En algunos casos permite la recuperación de terrenos degradados.

\section{Incovenientes:}

- Elevado consumo de terreno.

- Despilfarro de los recursos contenidos en los residuos.

- Despierta un importante rechazo social.

- Persistencia de los riesgos casi ilimitada en el tiem. po.

\subsection{Estructura del vertedero controlado}

Pese a la existencia de múltiples variantes, todas obedecen a un esquema común, resultante de la disposición de los residuos en capas sobre el terreno, que tras una mayor o menor compactación, se recubren con tierra u otro material, que también se compacta.

Las capas así formadas no se prolongan sin solución de continuidad, sino que como puede verse en la figura 1, se interrumpen a intervalos fijos mediante un recubrimiento lateral en pendiente. De esta forma se definen unidades menores denominadas células, elemento cuya repetición constituye la totalidad de la instalación.

En sentido vertical no se recomienda superponer más de 2 terrazas, con objeto de limitar los asentamientos y la producción de lixiviados y metano.

La terraza superior del vertedero se corona con una cobertura de mayor espesor destinada a aislar los residuos del exterior y a servir de base para el posterior uso de la superficie formada. La constitución de esta última capa dependerá por tanto del destino proyectado para estos terrenos. 


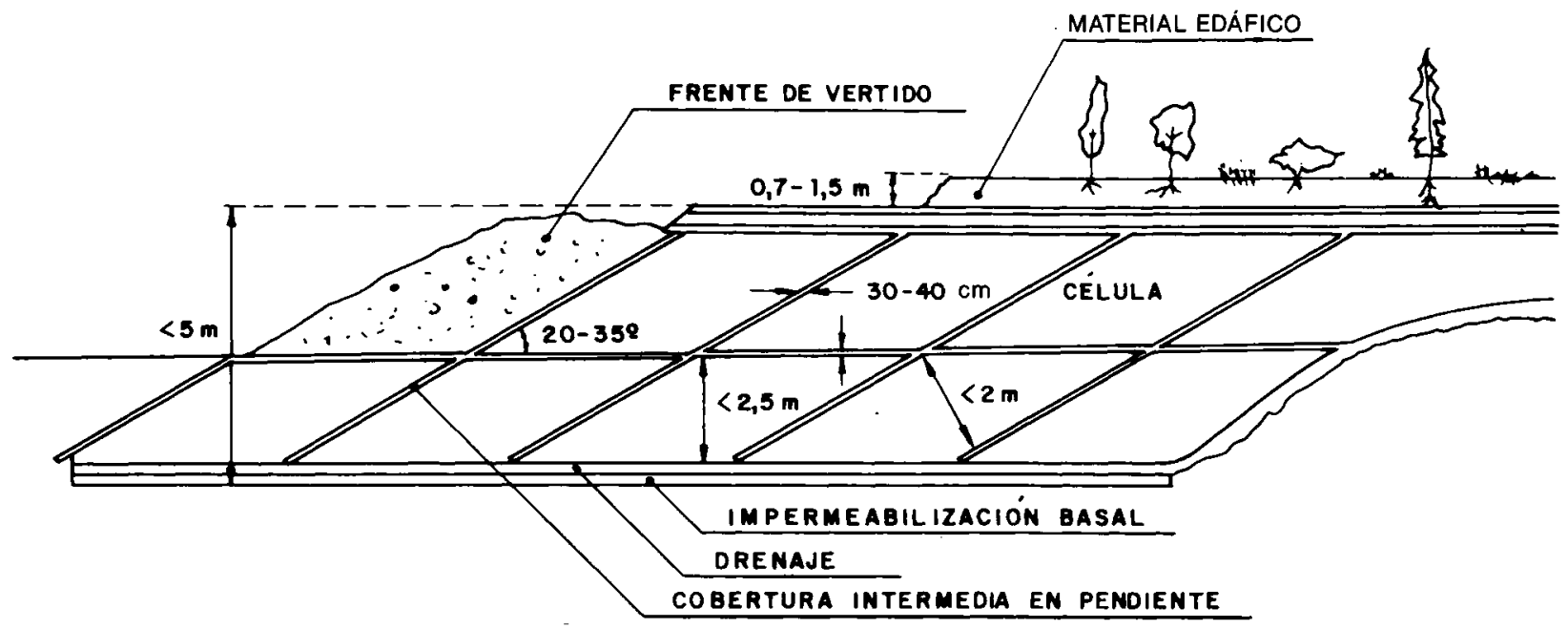

Fig. 1.-Esquema básico de un vertedero controlado.

TABLA 1

\begin{tabular}{|c|c|}
\hline Densidad de compactación & Consumo anual de superficie para una producción de $60 \mathrm{t} /$ dia. \\
$350 \mathrm{~kg} / \mathrm{m}^{3}$ & 3,06 Has. \\
$500 \mathrm{~kg} / \mathrm{m}^{3}$ & $1,1 \mathrm{Has}$. \\
$\# 800 \mathrm{~kg} / \mathrm{m}^{3}$ & 0,6 Has. \\
\hline
\end{tabular}

(\#) Modalidad de alta densidad sin recubrimiento.

En la figura 1 señalamos las dimensiones comúnmente recomendadas para los distintos elementos de la instalación.

El esquema descrito presenta una variante importante, correspondiente a los vertederos de alta densidad sin recubrimiento, donde se prescinde de las coberturas intermedias y sólo se dispone la final. El aumento de la densidad de los residuos (compactación) tiene como principal ventaja un menor consumo de superficie, si bien a riesgo de aumentar la producción de metano y lixiviados. Como vemos en la tabla 1 existe una amplia gama de situaciones entre los $350 \mathrm{~kg} / \mathrm{m}^{3}$ y los $1.000 \mathrm{~kg} / \mathrm{m}^{3}$ correspondientes a la modalidad de alta densidad sin recubrimiento.

\section{I.5. El material de cobertura}

Su elección es uno de los puntos claves en la ejecución del vertedero, con repercusiones en la selección de terrenos, pues éstos deben contar con fuentes de aprovisionamiento cercanas y explotables.

(c) Consejo Superior de Investigaciones Científicas

Licencia Creative Commons 3.0 España (by-nc)
Las características deseables en estos materiales son muy numerosas:

- Asequible en las proximidades del vertedero.

- Compactabilidad adecuada.

- Debe conferir estabilidad a la instalación.

- Debe constituir una base adecuada para la evolución de maquinaria.

- Resistencia a la erosión hídrica y eólica.

- No debe ser fácilmente encharcable.

- Debe impedir la entrada de agua en las células.

- Debe evitar la formación de polvo.

- Debe evitar el vuelo de residuos ligeros.

- Debe evitar la iniciación y propagación de incendios.

- Adecuado comportamiento respecto al desplazamiento de gases.

- Debe impedir las migraciones ascendentes de contaminantes.

- Debe limitar la entrada de insectos y no favorecer la construcción de madrigueras por roedores.

- Por último, debe ser compatible con la posterior utilización de los terrenos afectados por el vertido.

http://informesdelaconstruccion.revistas.csic.es 
TABLA 2

Comportamiento de materiales con distinta granulometría respecto a algunos factores exigibles a los recubrimientos de un vertedero controlado

\begin{tabular}{|c|c|c|c|c|c|}
\hline \multirow[b]{2}{*}{ FACTORES } & \multicolumn{5}{|c|}{ MATERIALES } \\
\hline & Gravas & Arenas & $\begin{array}{c}\text { Arenas } \\
\text { finas }\end{array}$ & $\begin{array}{c}\text { Arenas } \\
\text { arcillosas }\end{array}$ & Arcillas \\
\hline Estabilidad & B & B & $M$ & $\mathrm{R}$ & M \\
\hline Compactabilidad & B & B & $\mathrm{R}$ & $\mathrm{R}$ & $M$ \\
\hline Tránsito de maquinaria & B & B & $\mathrm{R}$ & $\mathrm{R}$ & $M$ \\
\hline Erosión hídrica & B & $R$ & $\mathrm{R}$ & $\mathrm{R}$ & M \\
\hline Erosión eólica & $B$ & $\mathrm{R}$ & $M$ & B & $\mathrm{R}$ \\
\hline Encharcamiento & B & B & $\mathrm{R}$ & $\mathbf{R}$ & $M$ \\
\hline Entrada de agua & M & M & M & B & B \\
\hline Formación de polvo & B & $R$ & $M$ & $\mathrm{R}$ & B \\
\hline Migración de contaminantes & B & B & $\mathrm{R}$ & $\mathrm{R}$ & M \\
\hline Roedores & B & B & $\mathrm{R}$ & $M$ & R \\
\hline Insectos & $\bar{M}$ & $M$ & $\mathrm{R}$ & B & B \\
\hline
\end{tabular}

$\mathrm{B}=$ Buen comportamiento. $\mathrm{R}=$ Aceptable. $\mathrm{M}=$ Malo.

Resulta prácticamente imposible que un solo material natural cumpla todos los requisitos deseables. Normalmente el uso de materiales artificiales o mezclas de varios naturales resulta económicamente inviable en el contexto del vertido controlado, por lo que un criterio técnico importante para la ubicación de estas instalaciones es la proximidad a fuentes de suministro de materiales aceptables para recubrimiento.

En la tabla 2 exponemos de forma simplificada el comportamiento de distintas granulometrias respecto a algunos de los requisitos expuestos.

La elección concreta del material adecuado depende de las condiciones que concurran en cada caso. En general se obtienen buenos resultados con arenas y gravas que presenten una fracción arcillosa, obteniéndose al menos parcialmente las ventajas combinadas de ambas granulometrias.

\subsection{Dinámica del vertedero controlado}

Desde el momento del vertido, hasta décadas después de su clausura, el vertedero controlado experimenta una serie de procesos de naturaleza física, química y biológica. El conocimiento de los mismos tiene una importancia doble respecto a la selección de emplazamientos: en primer lugar, las características del emplazamiento inciden sobre esta dinámica de manera importante. En segundo lugar, estos procesos pueden originar diversos impactos sobre el entorno natural y social del vertedero. A continuación describimos brevemente algunos de ellos:
1) Asentamientos: son desplazamientos descendentes de la superficie del vertedero por disminución en el volumen de los residuos que ocupan las células. Dicha disminución se produce fundamentalmente por la descomposición de los residuos orgánicos. El $90 \%$ del asentamiento se produce generalmente en los 5 primeros años, pero el proceso prosigue más lentamente durante décadas. Por ello la utilización de antiguos vertederos clausurados en usos que impliquen edificación, se ve seriamente limitada.

2) Procesos derivados de las altas temperaturas: las elevadas temperaturas que se producen durante la descomposición aerobia de los residuos orgánicos originan una aglutinación de los mismos, dando lugar a duras costras que dificultan la implantación de vegetación.

3) Procesos físicos derivados de agentes ambientales: los procesos erosivos tanto hídricos como eólicos revisten gran trascendencia y junto a otros como inundaciones, etc, serán comentados más detalladamente en el Apartado II.

4) Descomposición de la materia orgánica: Es uno de los procesos más relevantes de cuantos suceden en el interior de un vertedero controlado. Sus efectos más destacables son la emisión de gases (metano, sulfhídrico, hidrógeno, monóxido de carbono y sustancias orgánicas volátiles). En la figura 2 (5) puede observarse la dinámica de este proceso, que generalmente puede dividirse en las 5 etapas reflejadas, aunque la duración de las mismas es muy variable. 


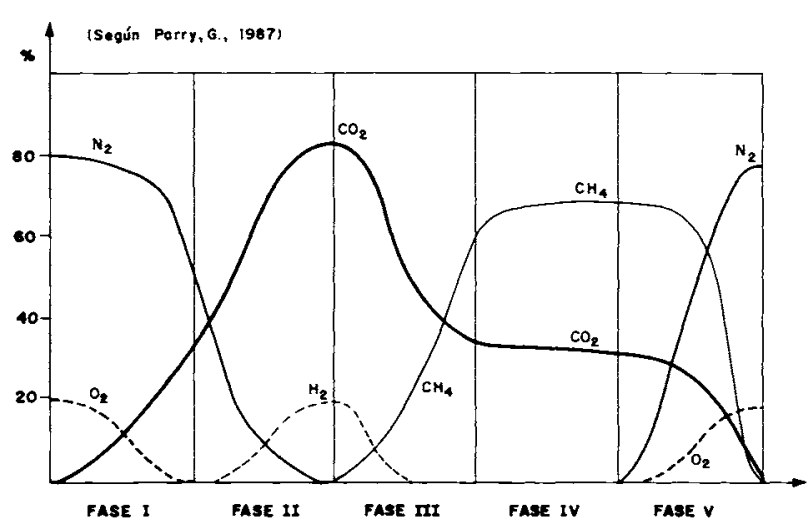

Fig. 2.-Evolución en la composición de la atmósfera de un vertedero controlado.

Las consecuencias prácticas de la descomposición de la materia orgánica pueden sintetizarse en tres efectos:

- Acidificación, que incrementa la movilidad de algunos contaminantes.

- Emisión de metano, que puede producir explosiones cuando su concentración en el aire se sitúa entre el 5 y el $15 \%$.

- Emisión de malos olores (gas sulfhídrico y otros gases orgánicos).

5) La producción de lixiviados: Es, sin duda, el proceso que representa un mayor riesgo ambiental y sanitario (contaminación de aguas superficiales y subterráneas). Los lixiviados son líquidos concentrados muy contaminantes formados en el interior de las células por la saturación de los residuos que contienen, como consecuencia, generalmente, de un aporte exterior de agua. Entre las sustancias que habitualmente contienen pueden citarse metales como el hierro, zinc y cobre; sales, fundamentalmente cloruros, sulfatos, nitratos y carbonatos; y solutos orgánicos como amonio, monóxido de carbono, sulfhídrico, metano, etc.
Los lixiviados suelen presentar una elevada proporción de sólidos en suspensión (mayor de $250 \mathrm{mg} / \mathrm{ll}$ ) y su pH suele ser ácido, en torno a 5,5.

La prevención de la problemática que puede causar una descarga de lixiviados debe abordarse con medidas tanto de localización como de ejecución:

- Los terrenos seleccionados deben ser hidrogeológicamente seguros (ya se verá más adelante cómo puede concretarse esta seguridad).

- Las condiciones hidrológicas del emplazamiento deben minimizar el riesgo de inundación y erosión hídrica a largo plazo.

- La cobertura debe limitar la entrada de agua en el vertedero y si es posible debe ser moderadamente alcalina.

- Deben arbitrarse medidas técnicas acordes con cada situación (canales de guarda, drenajes, sistemas colectores de lixiviados, etc).

- Todas las medidas mencionadas se tomarán en función de la climatologia local, debiendo extremarse en emplazamientos de elevada pluviometría o con frecuentes episodios torrenciales.

\subsection{Perspectivas a medio/largo plazo en la problemática de los residuos domiciliarios y su eliminación}

- El ritmo de producción de este tipo de residuos será previsiblemente creciente.

- En contrapartida, se incrementará la proporción de productos reutilizados, especialmente papel, vidrio, metales y materia orgánica.

- Se limitará la producción y difusión de sustancias tóxicas, especialmente en el ámbito doméstico.

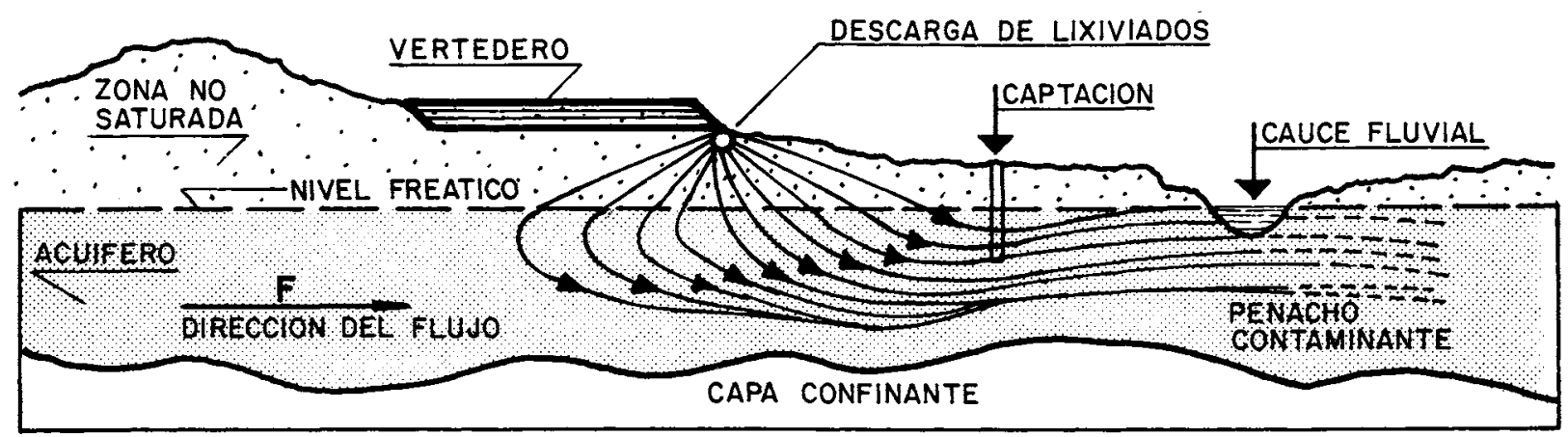

Fig. 3.-Esquema de la contaminación de un acuifero por una descarga puntual de lixiviados. Como puede verse la aureola contaminante se difunde homogéneamente en la zona no saturada para orientarse según las líneas de flujo una vez dentro del acuífero. 
- Se diversificarán los métodos de tratamiento y eliminación aplicables.

- Se combinarán diversos métodos en un mismo ám. bito territorial, incluso para un mismo tipo de residuos.

- Se impondrán normas más estrictas de seguridad que restringirán el campo de aplicación del vertido.

A la vista de estas previsiones es muy posible que los vertederos controlados restrinjan en un plazo más o menos largo su nivel actual de empleo y sobre todo su envargadura. Su uso se ajustará mejor a aquellas situaciones en que constituyan la solución óptima económica y ambiental al problema de los residuos. Sin embargo, es importante recordar que cualquier otro sistema de tratamiento o eliminación produce a su vez rechazos y residuos que deben finalmente disponer. se en vertederos controlados.

\section{REQUISITOS DEL TERRITORIO PARA LA UBICACIÓN DE VERTEDEROS CONTROLADOS}

A la vista de las características de estas instalaciones y siguiendo las directrices ya esbozadas, nos proponemos definir algunas condiciones tanto naturales como sociales y económicas que deben reunir sus emplazamientos. El carácter general de nuestro planteamiento impedirá concretar estos requisitos, lo que sólo se hará en ejemplos referidos a la comarca de Alcalá de Henares.

\section{II.1. Características climatológicas}

La climatología incide en aspectos fundamentales como la formación de lixiviados, la erosión, etc.

Los territorios en los que se plantea la selección de emplazamientos, normalmente limitados por el factor transporte, no suelen ser suficientemente amplios como para ofrecer grandes variaciones climatológicas. Por ello, en la mayoria de los casos, la climatología actuará como un condicionante general.

El año pluviométrico normal, serie de las precipitaciones medias mensuales, permite estimar la producción media de lixiviados en condiciones normales, que puede evaluarse teóricamente mediante expresiones del tipo:

$$
L=P-E-E T-A S(6)
$$

Donde:

L es la producción previsible de lixiviación;
P es la precipitación bruta caída sobre el vertedero;

E es la escorrentía sobre la cubierta del mismo;

ET es la evapotranspiración real, y

AS es la variación en el contenido de humedad de los residuos.

Entre estos factores hay 2 cuya determinación es especialmente difícil, pero que revisten gran importancia:

- La evapotranspiración real refleja la efectividad del clima para extraer agua del vertedero, y puede obtenerse de medidas lisimétricas directas o estimarse a partir de la evapotranspiración potencial.

- La capacidad de absorción de agua de los residuos depende de numerosos factores, pero según numerosas experiencias puede considerarse superior al $10 \%$ de su peso, lo que en vertederos convencionales supone entre 150 y $300 \mathrm{l} / \mathrm{m}^{2}$.

No es de extrañar, por tanto, que en nuestro ámbito climatológico la descarga de lixiviados sea excepcional en vertederos sometidos a pluviometrías menores de $500 \mathrm{~mm}$ anuales.

Sin embargo, estos valores pluviométricos medios son poco significativos por sí mismos, pues son las precipitaciones de intensidad extrema las que realmente comprometen la seguridad de la instalación, originando los siguientes riesgos:

- Erosión intensa del vertedero, especialmente ante escorrentías de carácter torrencial.

- Elevado aporte directo e indirecto de agua por sobrecarga y desestructuración de las protecciones perimetrales y la consiguiente descarga masiva de lixiviados.

- Inundación del vertedero.

- Arrastre de residuos hasta los cauces fluviales.

A pesar de que normalmente el tamaño de los territorios no permite en general seleccionar opciones con pluviometrias muy diferentes, el conocimiento de este factor es fundamental para fijar el grado de exigencia que debe aplicarse a otros criterios, fundamentalmente hidrológicos e hidrogeológicos.

Otros parámetros importantes dentro de la climatología son: 


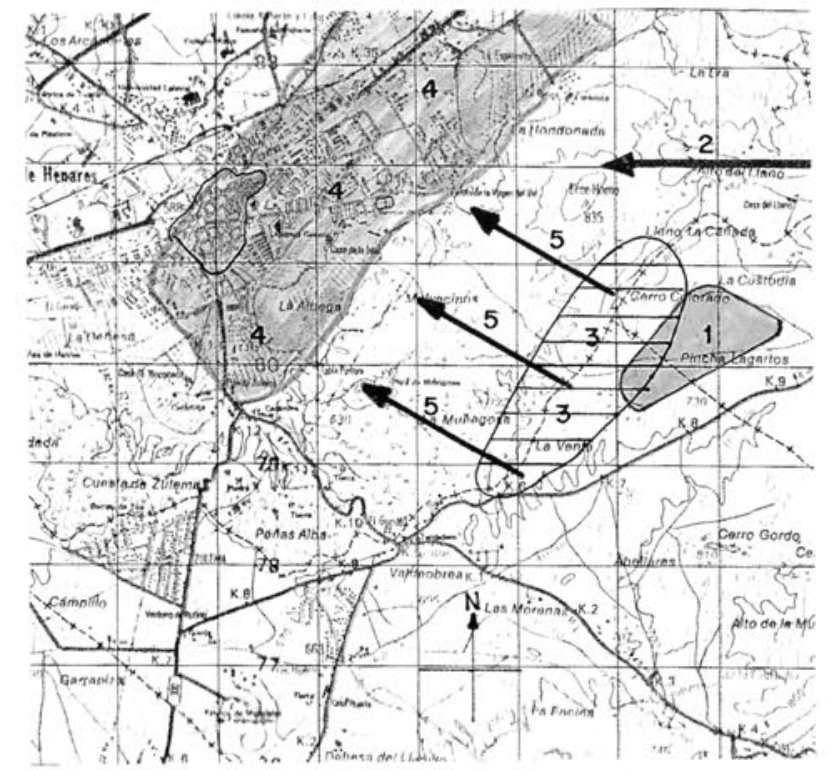

Fig. 4

La figura muestra la situación de uno de los recintos opcionales de vertido definidos en la comarca de Alcalá de Henares con respecto al régimen de vientos $y$ a posibles procesos de inversión térmica. Como puede observarse, a pesar de la distancia, existe algún ries go de incidencia sobre el área urbana de Alcalá. El significado de los números utilizados en la figura es el siguiente:

1.-Área opcional de vertido. 2.-Dirección de los vientos dominantes. 3.-Área con previsible incidencia de vientos fuertes. 4.-Zona urbana posiblemente afectada por frecuentes inversiones térmicas. 5.-Dirección de las brisas de ladera.

- RÉGIMEN DE VIENTOS, tanto regionales como locales, valorando su potencial erosivo y las posibles pautas de difusión de malos olores, especialmente en relación con núcleos poblados.

- Frecuencia de INVERSIONES TÉRMICAS que originan situaciones en las que se produce una deficiente depuración atmosférica.

\section{II.2. Características geológicas}

Como ya hemos mencionado, los terrenos en los que se asienta el vertedero y su substrato definen sus niveles de seguridad hidrogeológica a largo plazo. Por ello, la localización de emplazamientos geológicamente adecuados es uno de los pilares básicos en la ubicación de vertederos. Esta tarea puede dividirse en dos etapas claramente diferenciadas: en primer lugar se trata de eliminar todos aquellos terrenos hidrogeoló. gicamente muy vulnerables. Para ello se evalúan fundamentalmente los RECURSOS LITOLÓGICOS del territorio, aspecto de gran alcance del que generalmente contamos con un buen nivel de información.

Se trata de descartar para el vertido terrenos muy permeables:

- Sedimentos con importante permeabilidad intergranular.
- Materiales karstificables (calizas, dolominas, yesos, etc.).

- Rocas con permeabilidad por fisuración (ígneas y metamórficas principalmente).

Esta fase puede ir acompañada de datos hidrogeológicos sencillos que presenten un nivel de información suficiente, como la profundidad media del nivel freático. La aplicación de estos criterios puede eliminar grandes porciones del territorio, claramente contraindicadas y que no serán objeto de estudios posteriores.

En una segunda fase, preferiblemente concretando sobre una serie de emplazamientos opcionales, se valoran aspectos más complejos pero igualmente importantes como:

- Variación estacional de los niveles freáticos.

- Calidad y uso de las aguas subterráneas.

- Dirección del flujo en los acuíferos.

- Áreas de recarga y descarga.

- Potencia y tectónica de los materiales litológicamen. te aptos.

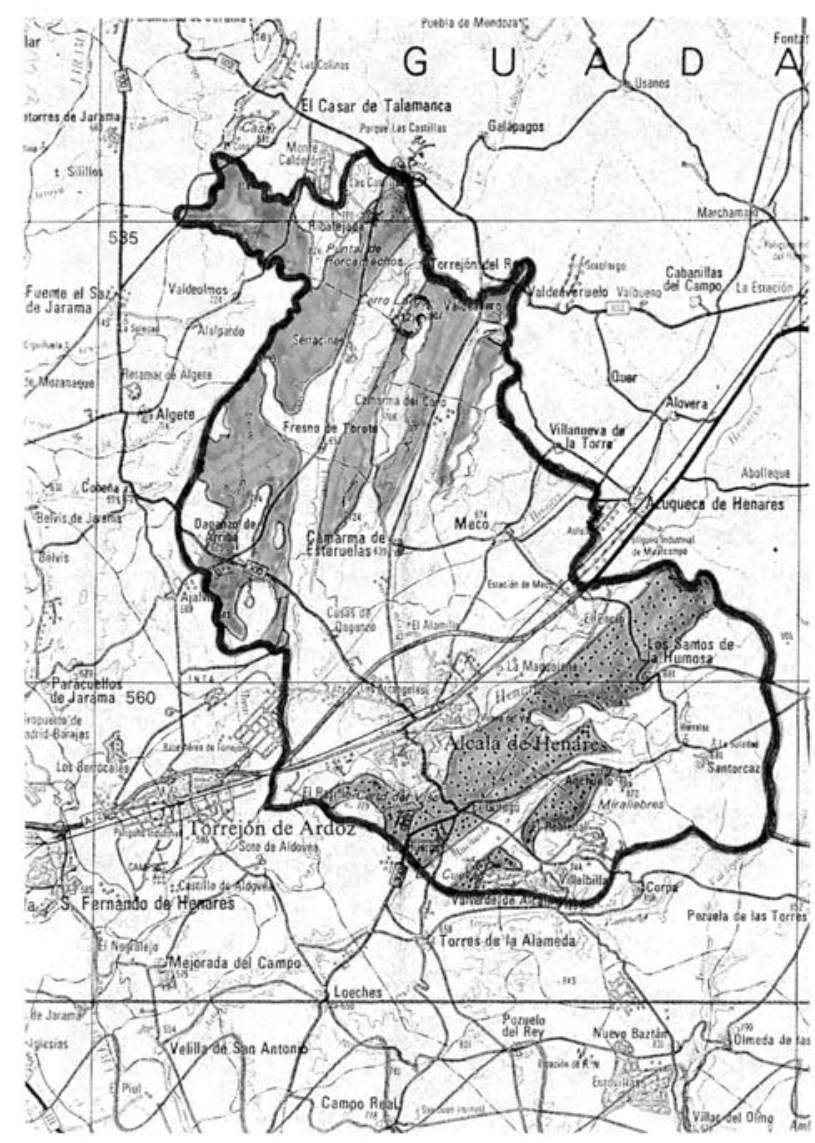

Fig. 5.-En esta figura se reflejan las áreas de la Mancomunidad de Henares que presentan una litología favorable al vertido (sombreado). Las áreas punteadas corresponden a zonas optimas desde el punto de vista litológico. 
Hay que destacar que, en esta escala detallada, la litología también juega un papel importante en la localización de posibles fuentes de suministro para la obtención de material de cobertura.

Por último, podría añadirse una tercera fase en el estudio geológico consistente en la verificación de los niveles de seguridad in situ mediante sondeos.

\section{II.3 La topografía}

Aspectos tan diversos como la seguridad hidrológica del emplazamiento, su idoneidad técnica o sus condiciones paisajísticas se encuentran fuertemente condicionadas por las variables topográficas.

Entre los datos que ofrecen destaca uno, la PENDIEN$\mathrm{TE}$, que como en el caso de la litología es capaz de descartar por sí sólo una amplia proporción de terrenos. Además, es uno de los pocos parámetros que ofrecen unos valores concretos de idoneidad, considerándose como adecuadas las pendientes menores al $8 \%$ (7), mientras que las situadas entre el 8 y $15 \%$ deberán evaluarse en función de otros factores que puedan interaccionar con la variable topográfica.

Algunos de los aspectos en que la topografía desempeña un papel relevante son:

- Configuraciones favorables al vertido.

- Capacidad del relieve para "absorber" la instalación sin discordancia paisajística.

- Detección de puntos con incidencia de vientos fuertes (collados, desfiladeros, divisorias, etc.).

- Valoración de singularidades topográficas de origen artificial como posible lugar de vertido.

Este último aspecto ha sido muy debatido, especialmente en lo referente al uso de canteras y minas a cielo abierto como vertederos. Pensamos que, en general, esta práctica no es recomendable por los siguientes motivos:

- La accidentada topografía artificial que rodea estos emplazamientos suele proporcionar un marco hidrológico inadecuado.

- Su carácter de depresión suele predisponer a inundaciones (concurrencia de escorrentía, afloramiento de nivel freático, etc.).

- Su idoneidad hidrogeológica debe ser verificada muy detalladamente, pues el elevado espesor del subsuelo aflorante aumenta la probabilidad de encontrar litologías inadecuadas.

- Generalmente el aprovechamiento económico de estas cavidades supondría acumular grandes espeso. res de residuos con los problemas que ello conlleva. Por el contrario, si no se colmata la cavidad, se pierde la única ventaja de esta práctica, que es su papel restaurador.

- La configuración de estos emplazamientos suele ser negativa favoreciendo la acumulación de metano y otros gases.

Sin embargo, pensamos que estas ubicaciones pueden ser muy adecuadas para residuos sólidos inertes que carecen de la problemática descrita y que podrian contribuir a la restauración de estos terrenos degradados.

\section{II.4. Criterios hidrológicos}

Se trata de localizar terrenos para el vertido con baja incidencia de riesgos hidrológicos y, por otro lado, de prevenir el acceso a la red fluvial de una eventual descarga de lixiviados.

Para el primer objetivo será necesario evaluar conjuntamente en todo el territorio la terna climatologíalitología-topografía que ya ha sido considerada. Como en los casos anteriores, también será necesario un estudio más detallado a nivel de localizaciones opcionales. Para ello creemos útil aplicar el concepto de cuenca vertiente asociada al emplazamiento (8), es decir, el área cuyas aguas vierten sobre el perímetro propuesto para la instalación.

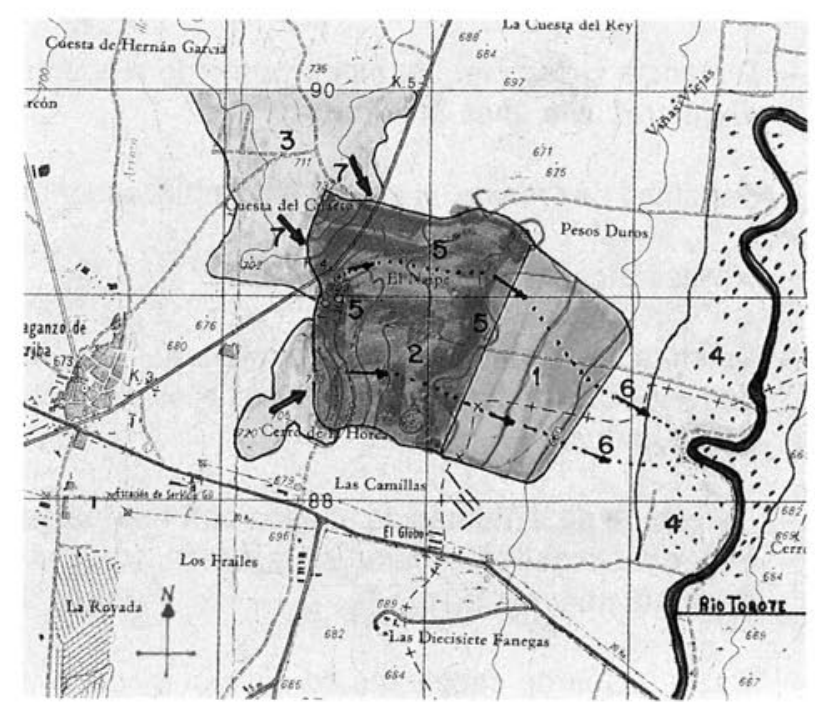

Fig. 6

En la figura podemos ver la cuenca asociada al emplazamiento III, que presenta la peculiaridad de limitar con dos acuiferos colgados cuaternarios, cuyas posibles descargas habrá que computar entre los aportes de agua a la cuenca. Los números utilizados son los siguientes:

1.-Área de vertido. 2.-Cuenca asociada a la misma. 3.-Acuíferos cuaternarios colindantes. 4.-Zona de ribera. 5.-Curvas de nivel de la cuenca (equidistancia $10 \mathrm{~m}$ ). 6.-Líneas naturales de drenaje. 7.Posibles puntos de descarga. 


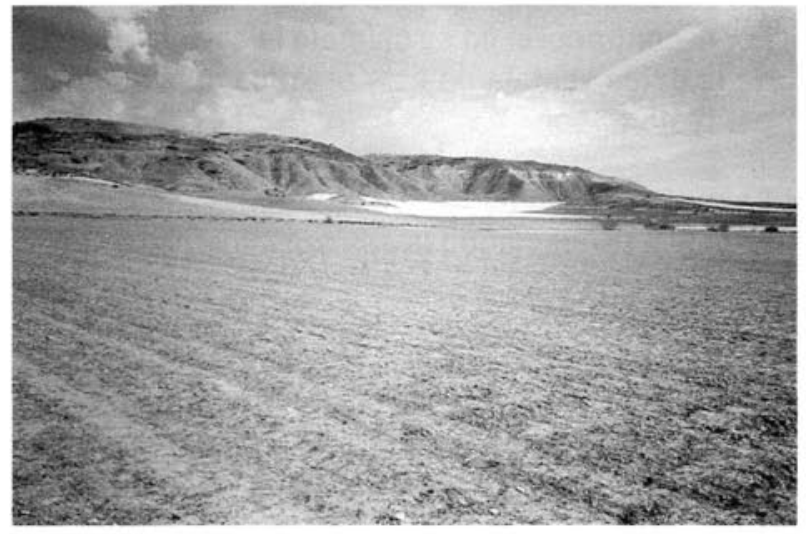

Foto 1.-En esta fotografía puede verse uno de los emplazamientos alternativos obtenidos en la comarca de Alcalá de Henares (II). No. tense los claros síntomas erosivos que se aprecian en los cerros del fondo, pertenecientes a la cuenca asociada al emplazamiento.

Bajo el contexto climatológico habrá que estudiar detalladamente determinados aspectos de la cuenca como pendientes, longitud de ladera, superficie, cubierta - vegetal, usos del suelo, etc.; todo ello destinado a estimar el nivel de riesgo hidrológico del emplazamiento, especialmente en circunstancias excepcionales. Como ejemplo, en la figura 6 se ofrece el esquema de una de las cuencas definidas en el proceso de selección llevado a cabo en la comarca de Alcalá de Henares.

En relación con el segundo objetivo habrá que considerar factores como:

- Distancia y desnivel del emplazamiento respecto al curso fluvial más próximo.

- Densidad de drenaje en el área del emplazamiento.

- Niveles alcanzados en las crecidas.

- Delimitación de las llanuras sedimentarias asociadas a los cursos fluviales y de otros entornos contraindicados.

- Detección de síntomas asociados con fuertes escorrentías erosivas (erosión en regueros, procesos de subfusión, etc.).

- Delimitación de cabeceras de cuenca incompatibles con el vertido.

\section{II.5. Aspectos floristicos y faunísticos}

La instalación de un vertedero acarrea la total desaparición de la cubierta vegetal en los terrenos afectados y de los hábitat animales que éstos albergaban. A este impacto cierto e inevitable hay que añadir otros

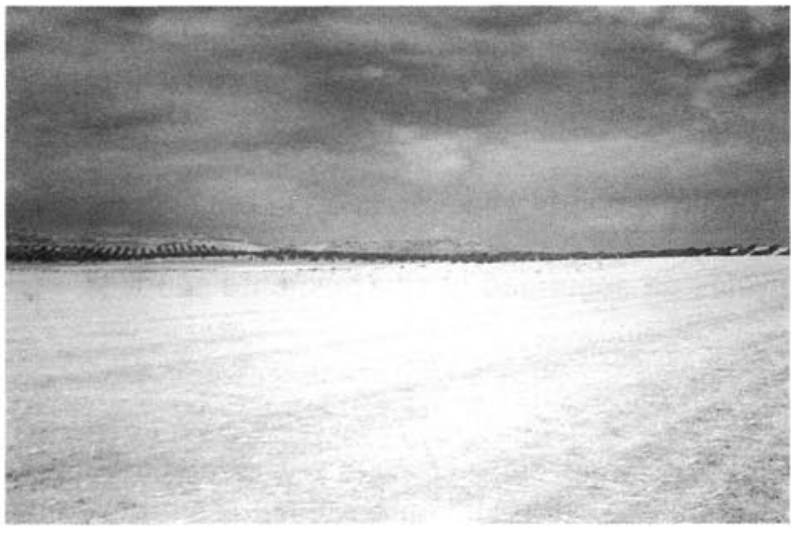

Foto 2.-La pobreza florística de los emplazamientos es deseable para la instalación de vertederos. En esta fotografía correspondien. te al emplazamiento IV, se observan además enclaves de olivar (al fondo) que pueden contribuir a la protección hidrológica y paisajis. tica del recinto de vertido.

que sólo se producirian ante un improbable fallo de la instalación, como el posible deterioro de los ecosistemas por contaminación (especialmente de los acuáticos) o incendios forestales. Mención especial merecen los riesgos derivados del acceso de anima. les al área de vertido, especialmente roedores, insectos $y$ aves, que pueden superar el cercado perimetral y encontrar en el vertedero alimento o hábitat adecuados. En estos casos puede producirse, a partir de estas comunidades, una difusión de productos tóxicos en las cadenas tróficas, e incluso hay que considerar su posible actuación como vectores infecciosos, lo que confiere una dimensión sanitaria al problema. Para evitar estas incidencias es fundamental una correcta elección del material de cobertura.

Entre las consideraciones generales a tener en cuenta para la selección de emplazamientos bajo esta óptica se pueden citar:

- Excluir ecotopos de especial interés.

- Evitar el contacto con áreas forestales que presenten elevado riesgo de incendio.

- Prevenir las incidencias sobre ecosistemas frágiles.

- Evaluar la presencia de especies animales problemáticas respecto al vertido.

- Considerar como muy favorables aquellos terrenos degradados o que presenten una especial pobreza faunistica y florística.

\section{II.6 El paisaje}

En el vertido controlado, la eliminación de la cubierta vegetal y la remodelación topográfica provocan generalmente apreciables impactos paisajísticos. Este efec- 


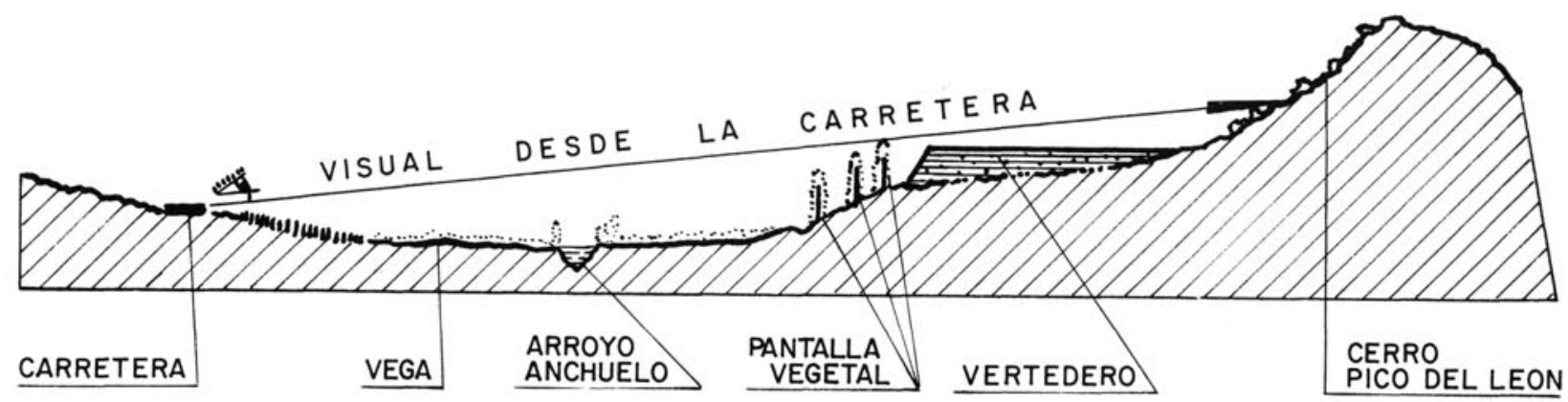

Fig. 7.-En la figura puede verse cómo pequeños accidentes topográficos pueden favorecer el ocultamiento del recinto de vertido. En este caso se trata de un perfil obtenido del Área IV (ver figura 13), en la que una pequeña convexidad favorece la eficacia del apantallamiento vegetal.

to negativo se incrementa por las cualidades negativas del material de trabajo, la basura, y por el posible efecto sinérgico de impactos no visuales, como ruidos y olores.

La ejecución del vertedero cuenta con técnicas de protección como apantallamientos vegetales, cercados, etc., pero vamos a citar algunas medidas a tomar en la fase de selección de emplazamientos:

- Evitar localizaciones que provoquen impactos añadidos como diseminación de residuos en áreas de vientos fuertes.

- Estudiar las posibilidades naturales de ocultación como colinas, barreras vegetales, etc, y adaptar a ellas los perímetros.

- Primar emplazamientos con cuencas visuales re. ducidas y poco concurridas.

- Estudiar el grado de mimetismo que puede presentar la instalación respecto a los terrenos colindantes, evitando las grandes discordancias cromáticas y morfológicas.

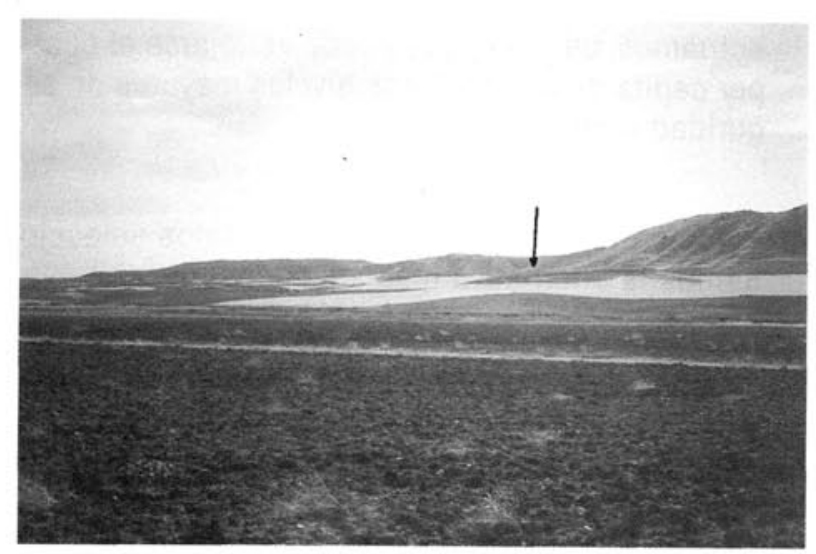

Foto 3.-Obsérvese la protección paisajistica que ejercen las coli. nas que aparecen en primer plano, ocultando casi totalmente el em. plazamiento I (véase figura 13).
- Excluir aquellos emplazamientos que supongan un deterioro de paisajes sobresalientes o singulares en su ámbito geográfico.

El paisaje es un recurso del territorio con una importante dimensión social, por lo que un emplazamiento mal seleccionado en este aspecto puede originar importantes rechazos, aun siendo apropiado desde otros puntos de vista.

\section{II.7. Usos del suelo actuales previstos}

Una de las claves del éxito de un emplazamiento es que no interfiera con otros usos productivos o socialmente valorados del suelo. Esta cualidad debe tener, además, cierto carácter de anticipación, adaptándose a posibles variaciones que pueden producirse en un futuro inmediato para inscribirse en el marco más amplio de la ordenación del territorio.

Dentro de las consideraciones prácticas, hay que excluir como emplazamientos para el vertido todos aquellos terrenos de elevada productividad, bien sea agricola, ganadera, industrial o de otro tipo.

Por otro lado, no deben interferirse usos del suelo que se asocien con importante presencia o afluencia de población, como sucede con las áreas recreativas, turísticas, vías de comunicación y, por supuesto, zonas residenciales y sus inmediaciones.

Respecto a este último punto, una decisión problemática suele ser la de que entorno de los núcleos poblados hay que excluir al vertido. Esto depende de numerosos factores (posible incidencia de molestias, perspectivas de expansión urbana, tamaño de la población, etc.), pero conviene, en general, disponer márgenes relativamente amplios que no suelen descartar una proporción significativa de terrenos aptos, pues en las inmediaciones de las poblaciones concurren numerosos factores de toda índole que desaconsejan el vertido (valor del suelo, densidad de infraestructuras, etc.). 


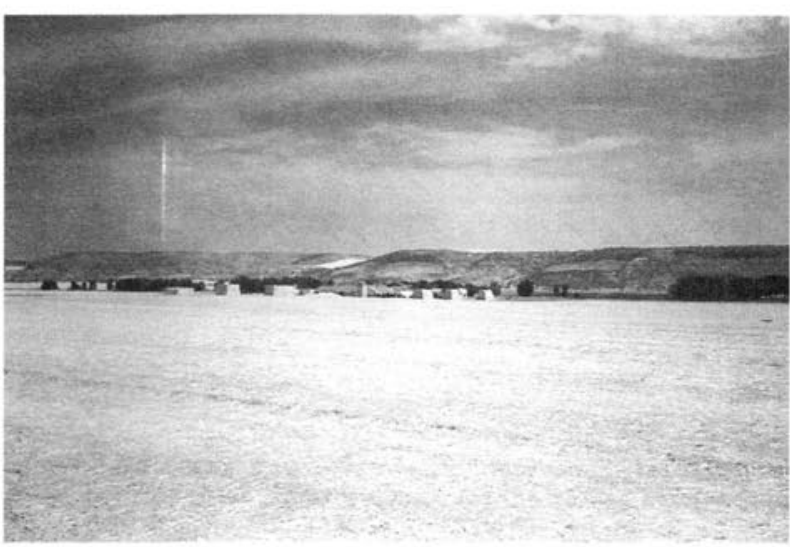

Foto 4.-Uno de los principales problemas del vertido es su incom patibilidad con otros usos del suelo. Aquí podemos ver la granja agropecuaria "El Colegio" que se vería seriamente afectada por la instalación de un vertedero en el área IV.

Por último, deben descartarse todos aquellos terrenos con especiales valores naturales (espacios a proteger), culturales, religiosos, artísticos 0 , en general, aquellos que sean valorados por los pobladores de la zona.

\section{II.8. La selección de terrenos desde un punto de vis. ta económico: el transporte y la dotación de in. fraestructuras}

Hasta ahora hemos visto las ventajas de escoger em. plazamientos en terrenos alejados y marginales. Sin embargo, la instalación y funcionamiento del vertedero exige otra serie de requisitos que se traducen en costos.

En primer lugar tenemos la matriz de costos unitarios de transporte, desde los distintos centros productores hasta los emplazamientos alternativos que consideremos. Sus valores dependen de:

- Distancias a través de la red viaria.

- Situación de la red viaria (tráfico, trazado, pendientes).

- Distancias a cubrir a través de accesos de nueva creacción.

- Dificultades de dichos accesos (puentes, desniveles, etc).

Análogamente pueden estimarse los costes asociados a cada emplazamiento en los capítulos de adquisición de terrenos, abastecimiento de agua, energía eléctrica, teléfono, aprovisionamiento de material de cobertura, etc. Generalmente los costes económicos debe- rán contraponerse a las características ambientales y sociales de cada emplazamiento para efectuar una evaluación comparativa que permita tomar una decisión. Sin embargo, en muchos casos, podrán eliminarse previamente aquellas opciones que presenten costos desmesurados $\sin$ aportar otras ventajas relevantes. Un caso práctico de este tipo de situaciones se plantea con los emplazamientos situados a distancias superiores a $20 \mathrm{~km}$ de los centros productores. En estos casos seria ineludible interponer una estación de transferencia para el transporte de los residuos, lo que sólo debe plantearse ante la inexistencia de emplazamientos adecuados más próximos.

\section{II.9. Algunas conclusiones sobre la estrategia de se- lección}

Sintetizando las líneas esbozadas en los apartados anteriores podemos distinguir las siguientes etapas en la selección de emplazamientos:

1) Fase de exclusión: utilizando criterios sencillos, capaces por si solos de descalificar terrenos y sobre los que existe un buen nivel de información, excluimos una buena proporción del territorio claramente incompatible con el vertido controlado.

2) Definición de alternativas: operamos sobre los terrenos no excluidos, seleccionando los mejor dotados y más representativos. Para ello aplicamos criterios más complejos y detallados obteniendo una serie de alternativas consolidadas.

3) Evaluación comparativa de las altenativas: explicitamos las ventajas ambientales de cada alternativa contraponiéndolas con sus costes económicos. Para ello empleamos, a ser posible, estimaciones de los costes asociados con cada una de ellas. Este binomio económico-ambiental debe referirse en forma de tasa a la población del territorio en que actuamos, de modo que pueda estimarse el coste per capita de obtener unos niveles mayores de seguridad ambiental.

4) Elección final: a la vista de estos datos seleccionamos la alternativa más adecuada.

En muchos casos prácticos el proceso de selección será más sencillo al agruparse de modo natural las etapas 2) y 3), especialmente cuando contamos con un reducido número de opciones. Por último, hay que recalcar que las condiciones básicas de seguridad ambiental deben cumplirse con certeza en todas las alternativas consolidadas que comparemos. 


\section{APLICACIÓN PRÁCTICA: LA SELECCIÓN DE TERRENOS APTOS PARA EL VERTIDO EN LA COMARCA DE ALCALÁ DE HENARES (MADRID) (8)}

En este último apartado describiremos brevemente algunos aspectos metodológicos y ejemplos prácticos resultantes de aplicar el proceso de selección, antes descrito, al territorio de la Mancomunidad del Henares, creada en 1986 dentro del Plan de Gestión de Residuos Sólidos de la Comunidad de Madrid.

\section{III.1. Breve descripción del territorio}

La Mancomunidad del Henares se sitúa en la zona centro-oriental de la provincia de Madrid, en su límite con la de Guadalajara. Cuenta con 10 municipios con una extensión de 40.009 Has. y una población de 151.648 habitantes de los que el $96,6 \%$ corresponden a Alcalá de Henares. En el territorio considerado, hay que distinguir una zona central, la Vega del Henares, ocupada en gran parte por el área urbana de Alcalá, muy densamente poblada y que centraliza la economía de toda la comarca. Al sur de la Vega, separada de ésta por una zona de cuestas, se encuentra el Páramo, de carácter netamente rural; al igual que sucede con los terrenos de la Campiña situados al norte de la Mancomunidad. Sin embargo, en ambas zonas se aprecia el influjo creciente de la expansión urbana alcalaína, especialmente en lo que se refiere a la proliferación de urbanizaciones residenciales.

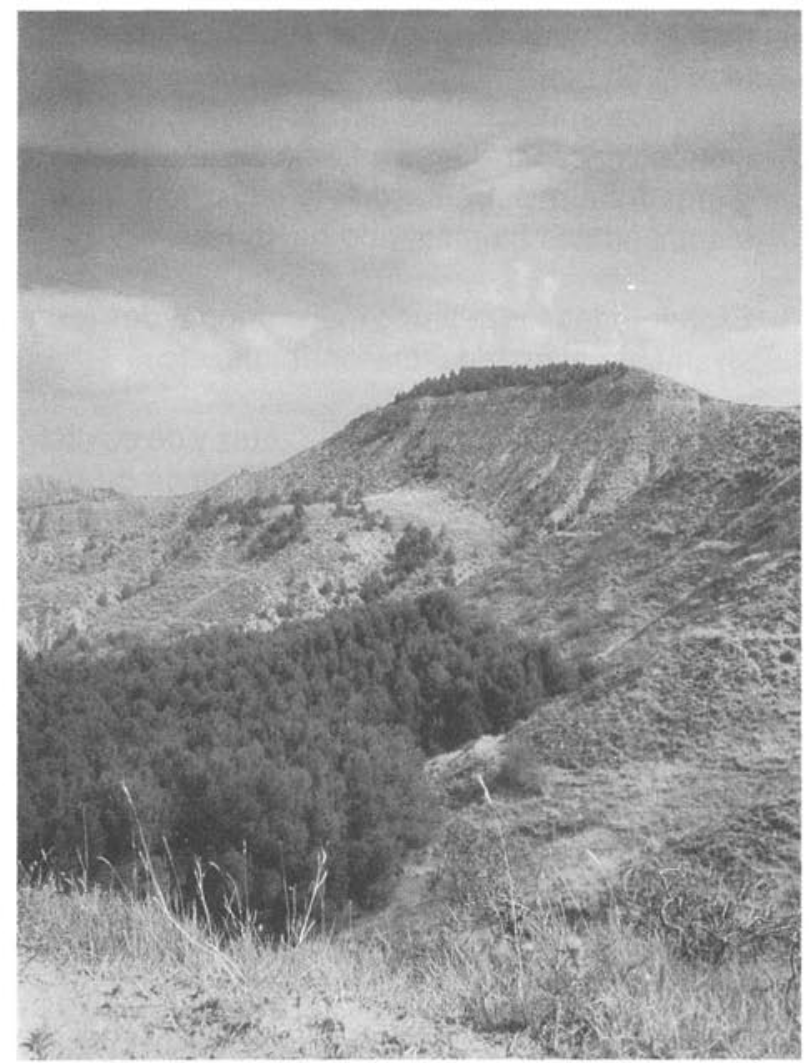

Foto 5.-Tipico paisaje de las Cuestas del Henares.

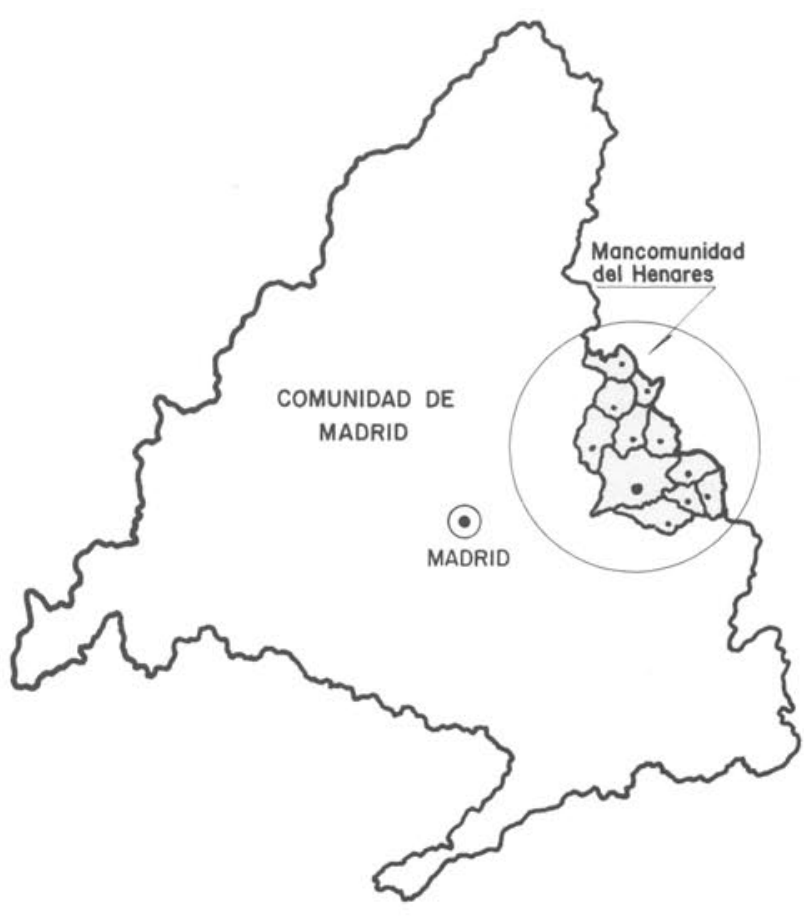

Fig. 8.-Situación geográfica de la Mancomunidad del Henares.

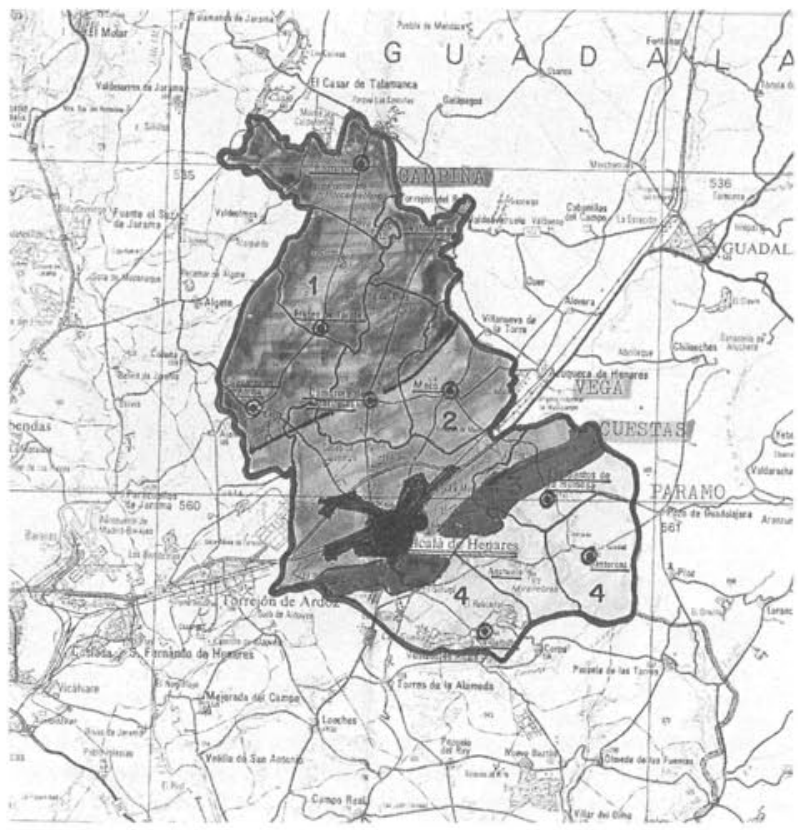

Fig. 9.

Subregiones de la Mancomunidad:

1.-Campiña. 2.-Vega. 3.-Cuesta. 4.-Páramo. 
La producción total de residuos domiciliarios y asimilables asciende en la comarca a 47.578 t/año, de las que 46.625 corresponden a Alcalá de Henares, mientras que los restantes municipios no superan en ningún caso las 350 t anuales. La centralización en Alcalá de la producción de residuos, así como el carácter radial de la red viaria simplifica en nuestro caso la evaluación del factor transporte.

\section{III.2. Aplicación de la fase 1: exclusión de terrenos}

La primera variable considerada es la climatológica, que, como suele suceder en estos territorios reducidos, presenta una notable homogeneidad, actuando como condicionante de los restantes criterios. En nuestro caso, 4 datos pueden ejemplificar el excelente comportamiento de esta variable respecto al vertido:

- Precipitación anual $<550 \mathrm{~mm}$.

- Precipitación mes más lluvioso $<60$ mm.

- Precipitaciones máximas en $24 \mathrm{~h}$. para un período de retorno de 100 años $<80 \mathrm{~mm}$.

\section{- Evapotranspiración real > $410 \mathrm{~mm}$.}

Las restantes variables si actúan como discriminante entre terrenos, y siguiendo la línea marcada en el Apartado II hemos seleccionado aquéllas de fácil evaluación, con abundante información y capaces por sí solas de descartar una importante proporción de territorio:

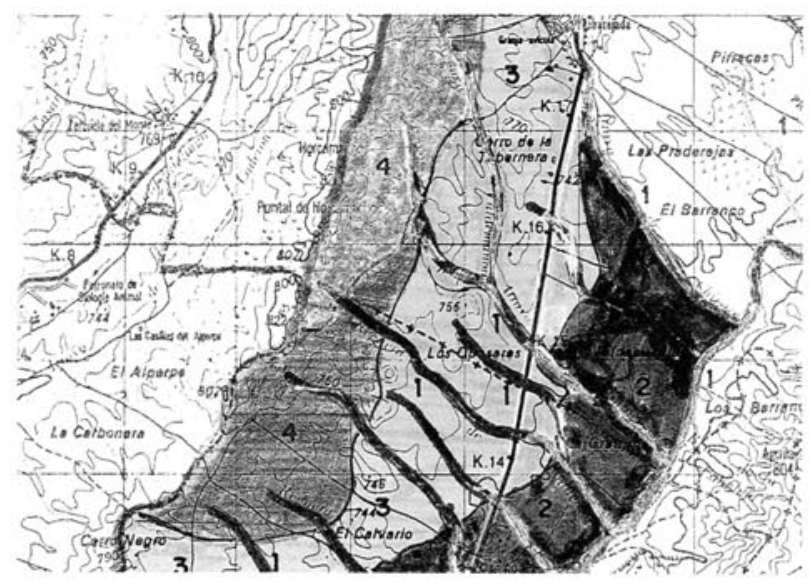

Fig. 10

Algunos criterios hidrológicos muy sencillos pueden evaluarse con. juntamente con los topográficos. En la figura puede verse una zona de la Campiña de litología adecuada eliminada por su elevada den. sidad de drenaje.

1.-Cauces de arroyos y barrancos. 2.-Zonas de vega cuaternaria. 3.-Áreas de litología compatible con el vertido. 4.-Cabeceras de arroyos y barrancos (sombreado). a) Variable litológica: descartamos todos los terrenos sedimentarios cuaternarios y los terciarios quimicos y asociados, lo que supone eliminar el $40 \%$ de la superficie comarcal.

b) Variable topográfica e hidrológica *: con criterios muy sencillos (pendientes superiores al $10 \%$, etc.) eliminamos el $84 \%$ de los terrenos no excluidos por la variable anterior.

c) Usos del suelo claramente incompatibles con el vertido, especialmente zonas urbanas y su entorno. La aplicación de este factor de exclusión elimina el $50 \%$ de los terrenos no excluidos en las variables anteriores.

Como resultado de este sencillo proceso, la superficie en la que cabe estudiar la posibilidad de un emplazamiento queda reducida a 1.350 Has., sobre las que habrá que definir las alternativas concretas.

\section{III.3. Fase 2: definición de alternativas}

El nivel más detallado de estudio que requieren los terrenos no excluidos (1.350 Has.) hace necesario definir unas alternativas concretas, sobre las que centrar dicho análisis. Para ello, en nuestro caso, hemos adoptado los siguientes criterios:

- Excluir todos los enclaves con superficie insuficiente para un horizonte de utilización de al menos 10 años, contando con los terrenos necesarios para instalaciones auxiliares y franja perimetral de seguridad. En nuestro caso esta superficie mínima recomendable ha resultado de $45 \mathrm{Has}$.

- Excluir todos los recintos mal conformados (excesivamente alargados, discontinuos, etc.)

- A la vista de los terrenos resultantes y de su distribución (ver figura 12) se decide prescindir de aquellas áreas situadas a más de $20 \mathrm{~km}$ de Alcalá de Henares, que además no presentan ninguna ventaja adicional.

Como consecuencia de este "filtrado", obtenemos 7 áreas que denominamos alternativas iniciales y cuya distribución puede observarse en la figura 12.

\footnotetext{
- La variable topográfica ha sido considerada simultáneamente con ciertos aspectos hidrológicos sencillos muy relacionados con ella (densidad de drenaje, proximidad a cauces, etc.). La aplicación de los distintos criterios ha seguido el orden de exposición $(a, b, c)$ de modo que se han aplicado primero aquellos que más terrenos descartan.
}

http://informesdelaconstruccion.revistas.csic.es 


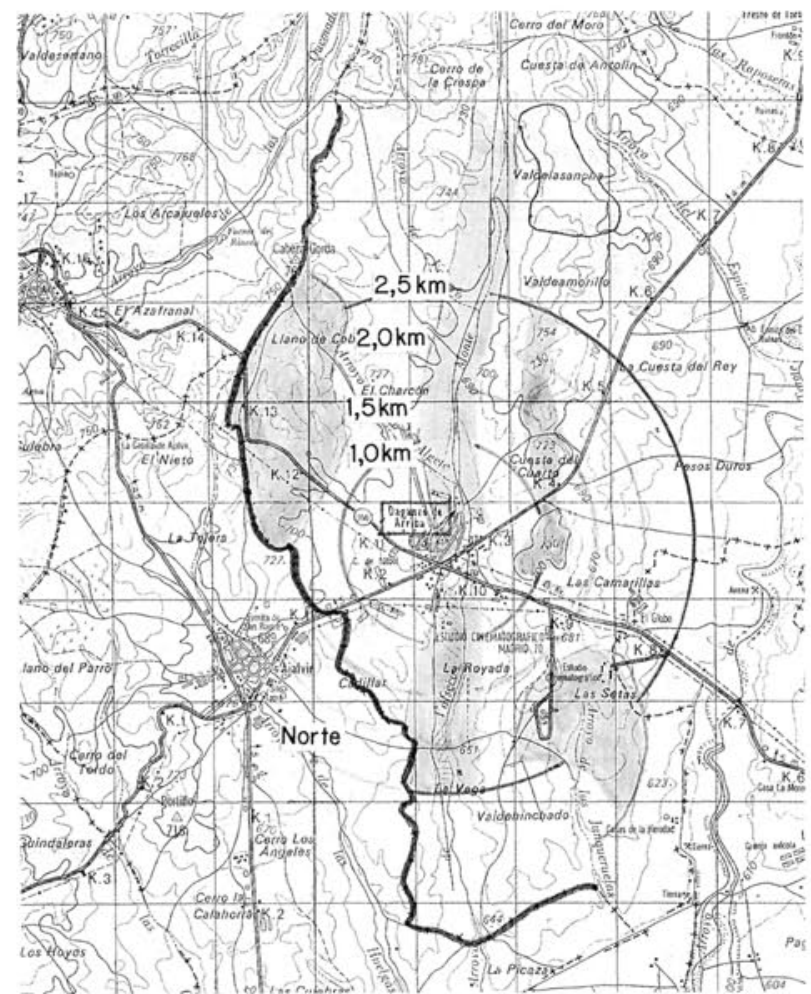

a

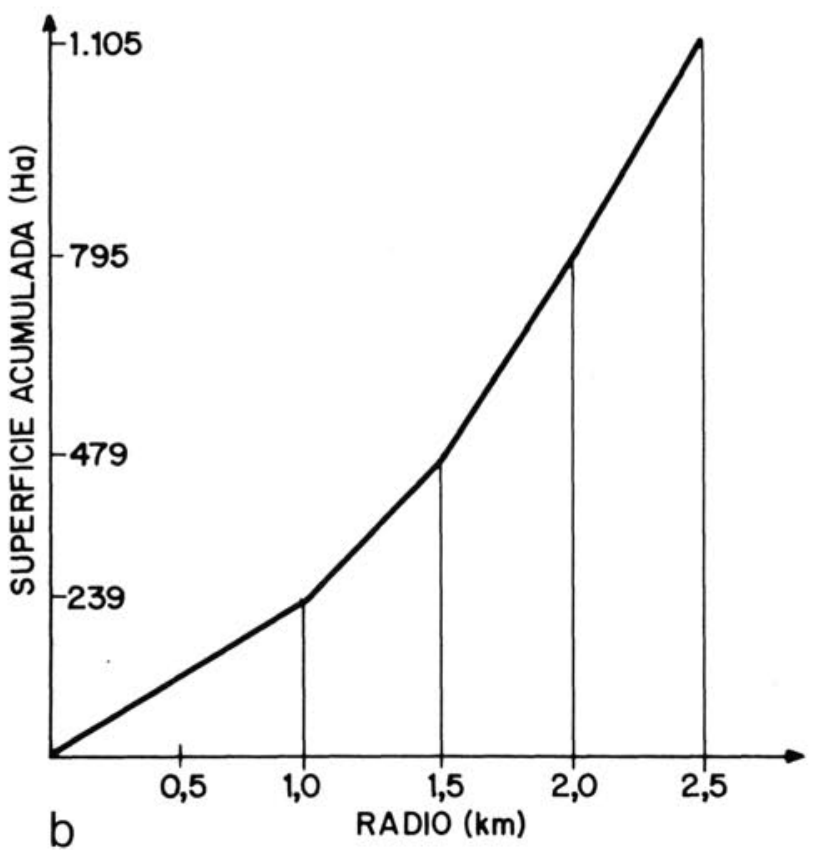

Figs. 11 a y $b$

En el mapa (11 a) pueden verse algunos posibles radios a excluir res. pecto al vertido tomados desde la población de Daganzo de Arri. ba, situada en la zona de estudio. También se reflejan (sombreada) las áreas contraindicadas por motivos ajenos a la presencia de la población.

En el gráfico (11 b) se refleja la pérdida de superficie potencialmen. te utilizable para el vertido asociada a cada radio de exclusión. En este caso concreto, el radio excluido debe ser mayor de $1 \mathrm{~km}$, pues en caso contrario resultaría excesivamente afectado el casco urbano. Así mismo, parece conveniente no superar los $1,562 \mathrm{~km}$, cifra a partir de la cual "se dispara" la superficie eliminada.
En este punto, conviene discernir si las 7 alternativas son realmente competitivas. Un examen más detallado muestra que 3 de ellas $(5,6$ y 7$)$ presentan condiciones claramente desfavorables y que pueden concretarse en:

- Costes de transporte que superan en más del $50 \%$ a las otras 4 opciones.

- Superficies muy ajustadas al mínimo exigido, lo que reduce su flexibilidad a la hora de definir el área de vertido.

- Situación poco favorable respecto a alguno de los criterios fundamentales: hidrogeológico, hidrológico o usos del suelo.

Por tanto estimamos que las opciones 1, 2, 3 y 4 son las realmente competitivas y las consideramos como alternativas consolidadas.

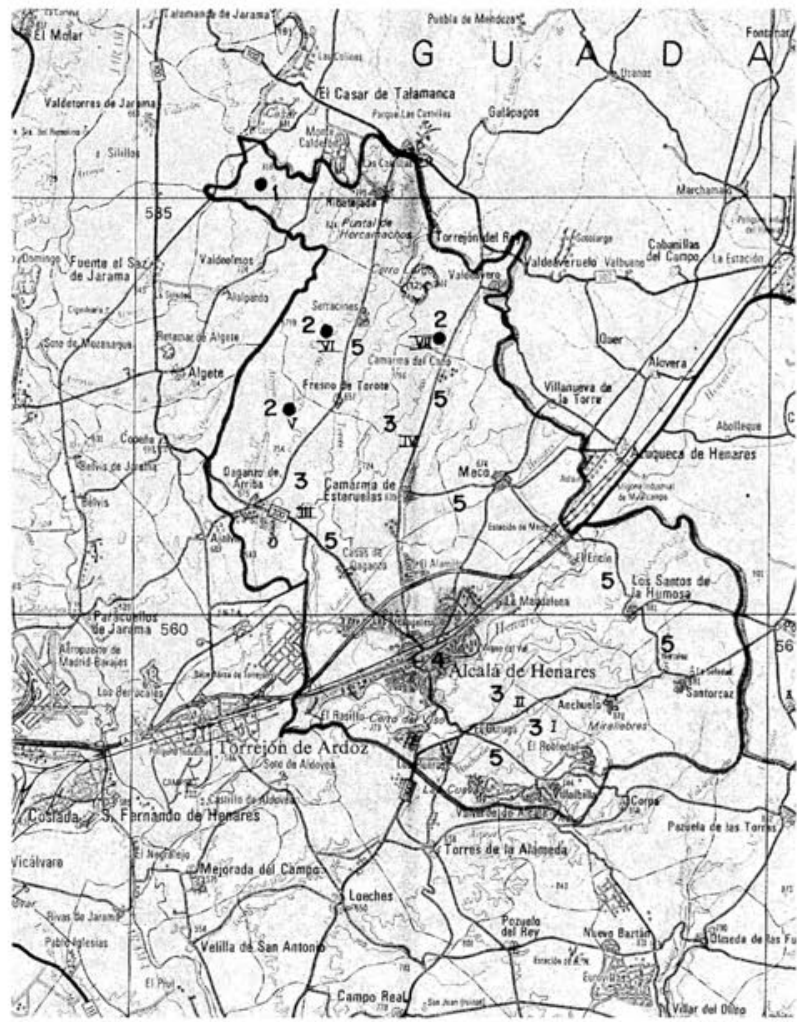

Fig. 12

En la figura se muestran las distintas alternativas consideradas en el proceso de selección:

1.-Alternativas eliminadas en la fase previa. 2.-Alternativas iniciales. 3.-Alternativas consolidadas (I a IV). 4.-También puede verse la distribución de las zonas productoras de residuos. 5.-Principales vías de comunicación que intervienen en su transporte. 


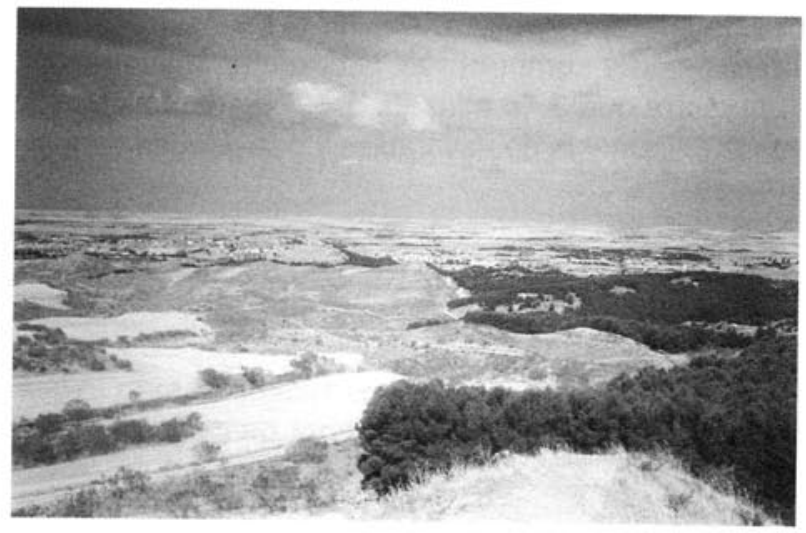

Foto 6.-Área colindante con el emplazamiento II sobre la que exis. te una importante demanda recreativa por su proximidad a Alcala y por contar con ciertos valores paisajisticos.

\section{III.4. Fase 3: evaluación comparativa}

Para concretar cada una de las alternativas consolidadas, definimos en cada una de ellas un recinto potencial de vertido, que en cada caso consideremos óptimo. En cada uno de estos 4 recintos realizamos un estudio comparativo de tres grandes bloques de variables:

- Bloque 1: Variables que determinan impactos de gran relevancia por su extensión, gravedad o significado:

1.1.: Características hidrogeológicas.

1.2.: Características topográficas e hidrológicas.

1.3.: Incidencia sobre núcleos poblados.

- Bloque 2: Variables que se asocian con impactos que, en nuestro caso, resultan limitados o menos severos:

\section{1.: Flora y fauna \\ 2.2.: Paisaje \\ 2.3.: Usos del suelo}

- Bloque 3: Variables de significado técnico-económico:

3.1.: Disponibilidad y asequibilidad de los terrenos.

3.2.: Situación respecto a infraestructuras y transporte.

3.3.: Disponibilidad de material de cobertura.

Los resultados de esta evaluación comparativa se ofrecen en la Tabla 3, donde caracterizamos cada emplazamiento respecto a las variables consideradas mediante 5 categorías, que se representan con un valor numérico:

- Valor 2: El emplazamiento presenta una situación optima respecto a la variable considerada.
- Valor 1: Corresponde a un comportamiento adecua. do, sin alcanzar las cotas máximas posibles.

- Valor 0: Representa una situación mediocre respecto al vertido, en el sentido de que es aceptable, pero factores no computados podrían originar deficiencias.

- Valor -1: Se adopta cuando el emplazamiento es deficiente respecto a alguno de los criterios, pero se trata de deficiencias subsanables o compatibles con el vertido.

- Valor \&: Se adopta cuando el emplazamiento es ina. ceptable respecto a alguna de las variables definidas, y su aparición implica la eliminación automática del emplazamiento.

Como cada bloque agrupa variables homogéneas independientes de los restantes, incluimos también una calificación para cada uno de los bloques, obtenida de la suma de los valores asignados a cada una de sus variables. Esta puntuación se corresponde con las siguientes categorias:

- Entre -3 y -1: DEFICIENTE

- Entre 0 y 2: MEDIOCRE

- Entre 3 y 4: ADECUADO

- Entre 5 y 6: OPTIMO

Como puede verse hemos prescindido de evaluaciones cuantitativas en el bloque 3. Esta decisión se apoya en dos razones:

- La diferencia de costes entre alternativas es muy reducida, y sus variaciones quedan absorbidas por el error de estimación.

- Los aspectos donde pudieran ser más significativas, como sucede con el valor del suelo, resultan difíciles de evaluar.

Por tanto, en nuestro caso concreto, hemos preferido dar una calificación cualitativa, que además describe mejor aspectos no estrictamente económicos.

\section{III.5. Elección final}

A la vista de la Tabla 3 resulta evidente que dos de las alternativas (1 y 4) son netamente superiores. Ambas son plenamente adecuadas para la instalación de un vertedero controlado, por lo que la decisión puede considerarse abierta y ambos emplazamientos deben ser tomados como resultado satisfactorio del proceso de selección.

A título de recomendación, pensamos que el área l es ligeramente más favorable: 
TABLA 3

\section{VARIABLES}

\section{ALTERNATIVAS}

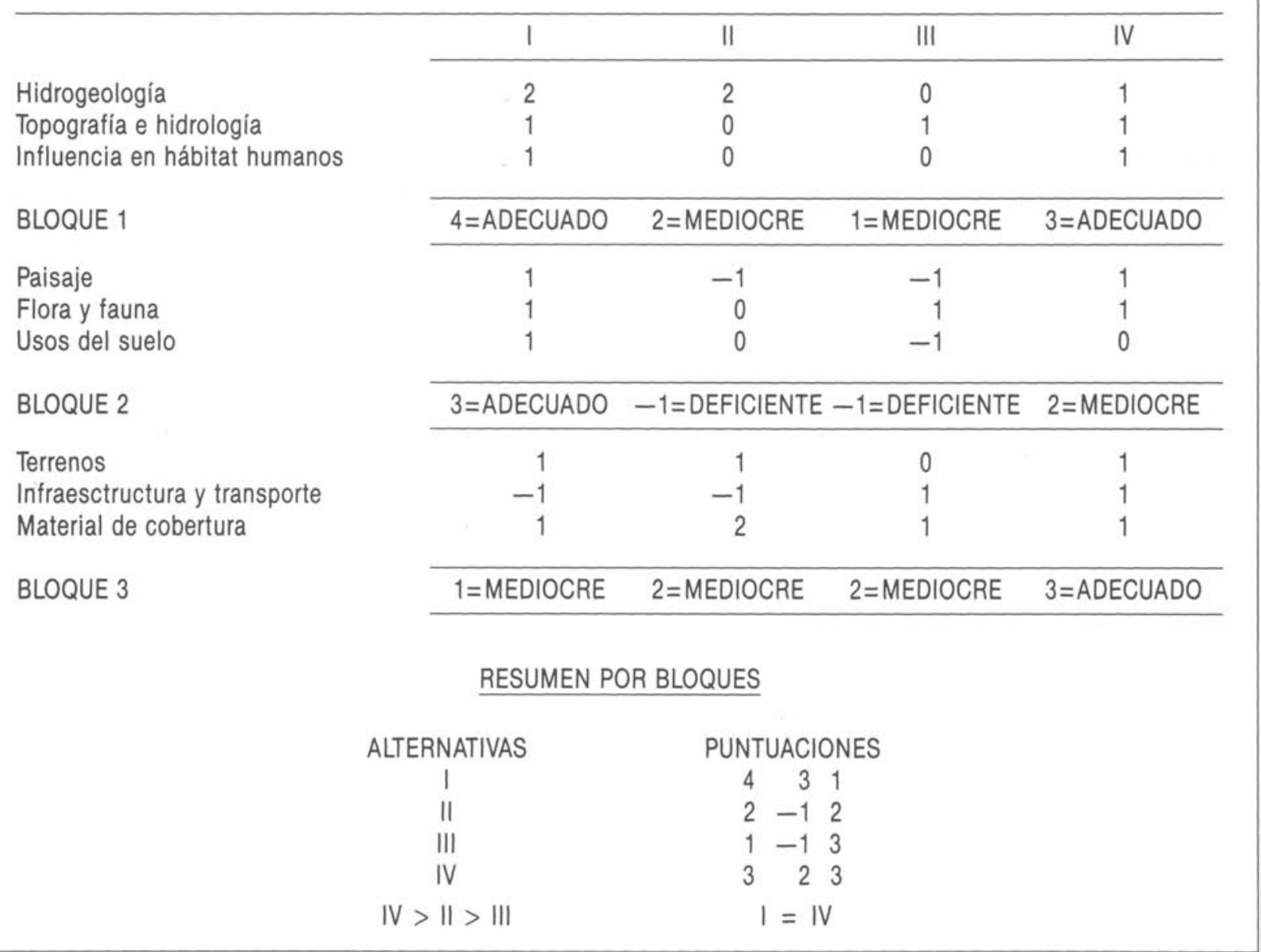

1) Presenta unos niveles de seguridad hidrogeológica realmente excepcionales, suficientes incluso para la instalación de un depósito de seguridad para residuos tóxicos.

2) Su principal inconveniente se plantea por una deficiente dotación de infraestructuras, pero pensamos que esta carencia no reviste gravedad y desde una perspectiva económica queda en parte compensada por la escasa productividad de los terrenos que ocupa, inferior a los de la alternativa 4.

3) En esta última opción (4), el rechazo social será previsiblemente mayor, debido al desarrollo residencial que se observa en sus proximidades.

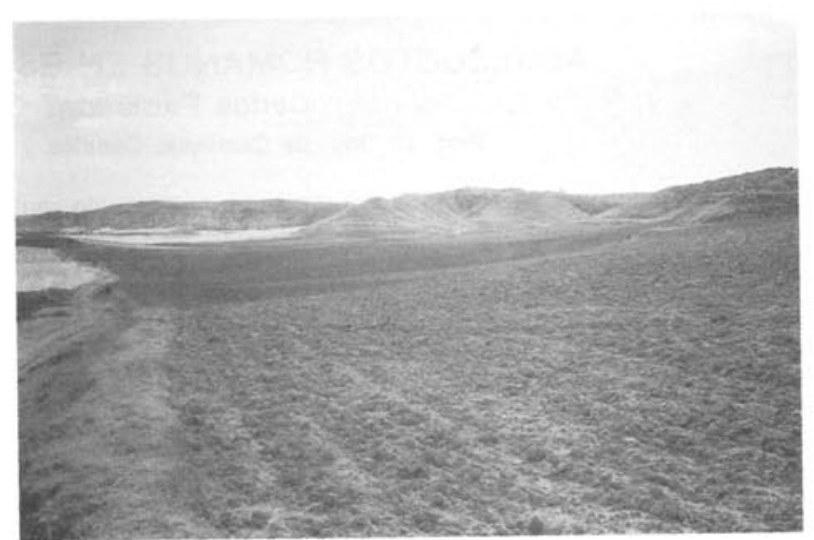

Foto 7.-Interior del recinto I. Nótese su pobreza florística y su suave topografía. 


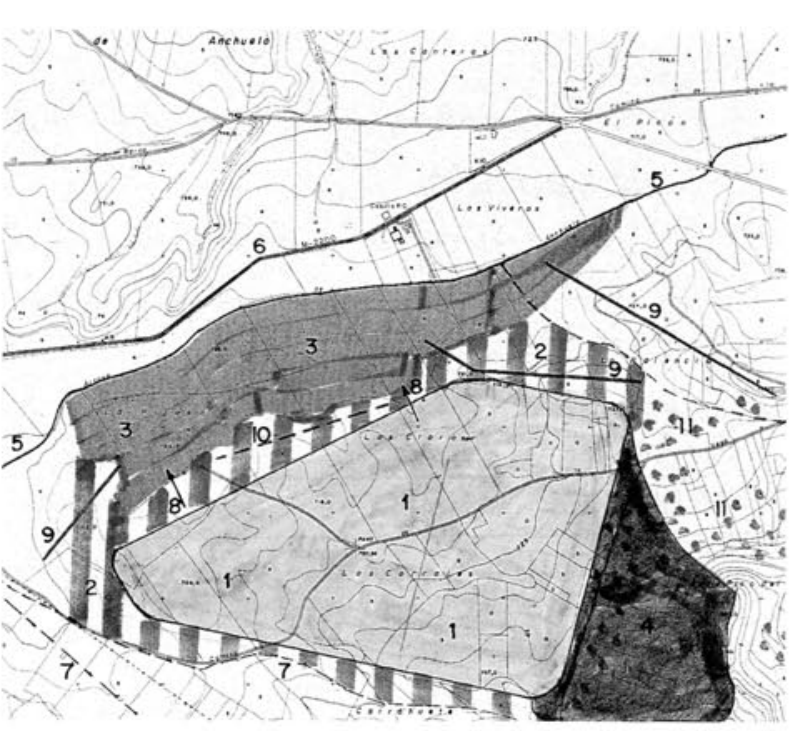

Fig. 13

Plano de un potencial recinto de vertido constituido por terrenos de la alternativa I. En la figura pueden observarse:

1.-Área propuesta para la instalación del vertedero. 2.-Terrenos co. lindantes que deben actuar como perimetro de seguridad. 3.-Zona aluvial ocupada por cultivos de regadio, especialmente sensible res. pecto al vertedero. 4.-Cuenca vertiente asociada (nótese su reducida extensión). 5.-Curso fluvial más próximo. 6.-Carretera asfaltada más próxima. 7.- Líneas de drenaje natural. 8.-Puntos con mayor riesgo de presentar una descarga superficial de lixiviados. 9.-Linea de relieve natural que actúa como pantalla visual de instalación respecto a la carretera ocultándola totalmente. 10.Ocultándola parcialmente. 11.-Enclaves de olivar que pueden contribuir a la protección hidrológica y paisajistica del vertedero.

\section{BIBLIOGRAFIA}

1. OTERO PERAL, L.: "Residuos sólidos urbanos". M.O.P.U., 1988.

2. LOPEZ GARRIDO, J. et al: "Basura urbana. Recogida, eliminación y reciclaje". Editores Técnicos Asociados. Barcelona, 1975.

3. INSTITUTE FOR SOLID WASTE OF AMERICAN PU. BLIC WORKS ASSOCIATION (I.S.W.A.P.W.A.): "Municipal refuse disposal". Chicago, Public Administration Service, 1966. (Versión en castellano: Instituto de Estudios de Administración Local. "Tratamiento de residuos urbanos". Madrid, 1976.

4. HAYNES, R. C.: "Main types of contaminants". Publicado en: "Reclamating contaminated land". London, 1987.

5. PARRY, G. D. R. and R. M. BELL: "Types of contaminated land". Publicado en "Reclamating contaminated land". London, 1987.

6. AGENCIE NATIONALE POUR LA RECUPERATION ET L'ELIMINATION DES DECHETS (A.N.R.E.D. -Angers-France), BUREAU DE RECHERCHES GEOLOGIQUES ET MINERES (B.R.G.M. -Orleans-France), INSTITUT DE RECHERCHES HYDROLOGIQUES (I.R.H. -Nancy-France): "Evaluation of leachates volumes on landfill sites". Programe de R\&D "Protection de l'enviroment".

7. GLADE, F: "Sanitary lanfill site selection and managment". Harrisbury, 1979. Publicado en: "Planing the uses and management of land". Serie Agronomy num. 21, 1979.

8. POZO MANRIQUE, M.: "La ubicación de vertederos controlados. Aplicación a la selección de emplaza. mientos en la Comarca de Alcalá de Henares". (Proyecto fin de carrera, sin publicar) E.T.S.I.M. Madrid, 1990.

\section{publicación del ICCET/CSIC}

\section{ACUEDUCTOS ROMANOS EN ESPAÑA Carlos Fernández Casado \\ Prof. Dr. Ing. de Caminos, Canales y Puertos}

Esta publicación se compone de una serie de articulos, publicados en la Revista "Informes de la Construcciónn, en los cuales se hace un análisis de los acueductos romanos que existen en España y el balance de las condiciones de conservación en que se encuentra cada uno de ellos, incluyendo referencias históricas y literarias. Se ha ilustrado con la reproducción de la valiosa documentación gráfica que posee el prestigioso autor.

Un volumen encuadernado en couché, a dos colores, de $21 \times 27$ centimetros, compuesto de 238 páginas, numerosos grabados, dibujos, fotos en blanco y negro y figuras de linea.

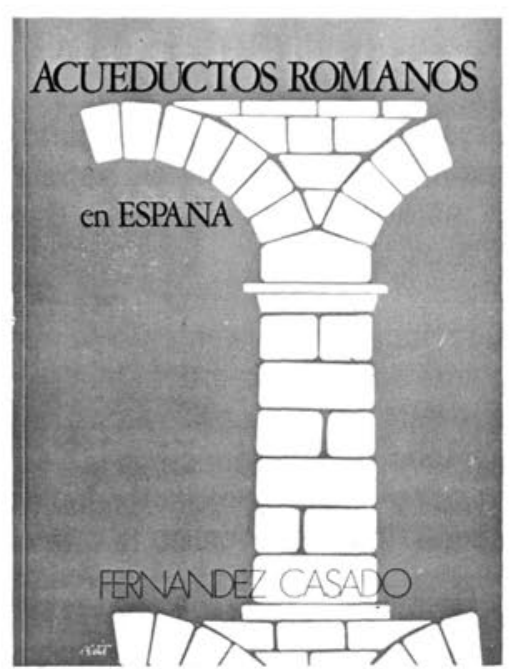

